\title{
Desenvolvimento de afilhos e componentes do rendimento em genótipos de trigo sob diferentes densidades de semeadura
}

\author{
Igor Pirez Valério(1), Fernando Irajá Félix de Carvalho ${ }^{(1)}$, Antonio Costa de Oliveira ${ }^{(1)}$, \\ Amauri de Almeida Machado(2), Giovani Benin(3), Pedro Luiz Scheeren ${ }^{(4)}$, \\ Velci Queiróz de Souza ${ }^{(1)}$ e Irineu Hartwig(5)
}

\begin{abstract}
(1)Universidade Federal de Pelotas (Ufpel), Faculdade de Agronomia Eliseu Maciel, Departamento de Fitotecnia, CEP 96010-900 Pelotas, RS. E-mail: igorvalerio@gmail.com, carvalho@ufpel.tche.br, antonio.oliveira@pq.cnpq.br, velciq@gmail.com (2)Ufpel, Faculdade de Matemática, Instituto de Física e Matemática. E-mail: amachado@ufpel.tche.br (3)Universidade Tecnológica Federal do Paraná, Departamento de Fitotecnia, CEP 85501-970 Pato Branco, PR. E-mail: giovani.bn@gmail.com (4)Embrapa Trigo, Caixa Postal 451, CEP 99001-970 Passo Fundo, RS. E-mail: scheeren@cnpt.embrapa.br ${ }^{(5)}$ Syngenta Seeds, Unidade de Pesquisa e Desenvolvimento, Caixa Postal 02, CEP 85825-000 Santa Tereza D'Oeste, PR. E-mail: irineu.hartwig@syngenta.com
\end{abstract}

\begin{abstract}
Resumo - O objetivo deste trabalho foi determinar o padrão de desenvolvimento de afilhos em genótipos de trigo contrastantes para esse caráter, em diferentes densidades de semeadura, bem como seus efeitos sobre os componentes do rendimento de grãos. O experimento foi conduzido no Município de Capão do Leão, RS, em 2006. Dez cultivares de trigo, selecionadas com base na capacidade de afilhamento, foram utilizadas em delineamento de parcelas divididas, com a parcela composta pelo fator cultivar, e as subparcelas pelas densidades de semeadura, com 50, 200, 350, 500 e 650 sementes aptas por metro quadrado. Observou-se que a senescência de afilhos esteve diretamente relacionada ao potencial de afilhamento dos genótipos. Os genótipos com elevada capacidade de afilhamento apresentaram efeito mais pronunciado da senescência, com o aumento da densidade de semeadura. $\mathrm{O}$ melhor ajuste dos componentes do rendimento foi obtido por meio da adequada densidade de semeadura, que deve ser realizada com base no potencial de afilhamento dos genótipos. Além disto, o efeito compensatório de genótipos com reduzido potencial de afilhamento é resultante de maior massa de grãos por espiga, em detrimento do número de espigas por unidade de área.
\end{abstract}

Termos para indexação: Triticum aestivum, estádio de desenvolvimento, potencial de afilhamento, senescência, sobrevivência de afilhos.

\section{Tiller development and yield components in wheat genotypes under different seeding densities}

\begin{abstract}
The objective of this work was to determine the developmental pattern of tillers in wheat genotypes showing contrasting number of tillers. The genotypes were tested under different seeding densities, in order to evaluate their effect on grain yield components. The experiment was performed in Capão do Leão County, Rio Grande do Sul State, Brazil, in 2006. Ten wheat cultivars, selected by their tillering ability, were tested in a split plot design, where plots were formed by the genotype (cultivar), and subplots by different seeding densities: 50, $200,350,500$ and 650 seeds per square meter. Results indicated that tiller senescence is directly correlated to tillering potential of the genotypes, and genotypes with higher tillering ability presented higher senescence values, when subjected to higher seeding densities. The best adjustment of yield components is obtained from the adequate seeding density, which can be achieved by matching the density and tillering potential. Also, higher yield in genotypes with reduced tillering potential is achieved by increasing grain mass per ear, to compensate for their lower number of ears per area unit.
\end{abstract}

Index terms: Triticum aestivum, developing stages, tillering potential, senescence, tiller survival.

\section{Introdução}

A emissão, o desenvolvimento e a sobrevivência dos afilhos são de extrema importância para a cultura do trigo (Triticum aestivum L.). Este caráter está diretamente relacionado ao número de espigas por unidade de área e indiretamente aos componentes do rendimento: número de grãos por espiga e massa de grãos (Davidson \& Chevalier, 1990). Um dos motivos da baixa produtividade média das lavouras de trigo, no Brasil, tem sido atribuído à pequena participação de afilhos férteis na formação do rendimento final (Mundstock, 1999). 
Esse problema está relacionado à grande diversidade no padrão de afilhamento dos genótipos de trigo, o que faz com que não haja clareza nos critérios para a escolha da densidade de semeadura mais adequada. Isto determina que, em muitos casos, não exista relação direta entre número de afilhos férteis e rendimento de grãos (Sparkes et al., 2006). Isto se deve, em parte, não só às diferenças no padrão de afilhamento dos genótipos em cultivo, mas também à presença do forte efeito da interação genótipo $\mathrm{x}$ ambiente, relacionados à emissão e à sobrevivência de afilhos (Ozturk et al., 2006).

Os efeitos de ambiente e de manejo sobre a expressão da capacidade de afilhamento têm sido estudados em diversos trabalhos, e a densidade de semeadura foi identificada como uma das técnicas culturais que mais influenciam o rendimento de grãos e seus componentes (Ozturk et al., 2006; Sparkes et al., 2006). A maximização do rendimento de grãos em relação à densidade de semeadura está fortemente relacionada ao potencial do genótipo em produzir afilhos férteis, o que também influencia, de forma direta, o número de espigas produzidas por unidade de área (Ozturk et al., 2006).

A manutenção do rendimento de grãos, com diferentes densidades de plantio, é atribuída à compensação nos demais componentes do rendimento de grãos (Holen et al., 2001), uma vez que o trigo apresenta elevada capacidade de compensar a falta ou excesso de um componente pela modificação ou ajuste nos demais componentes (Freeze \& Bacon, 1990).

O conhecimento da habilidade do efeito compensatório entre os componentes do rendimento, de genótipos que apresentam diferente potencial de afilhamento, é de fundamental importância para a recomendação de técnicas de manejo diferenciadas, a fim de melhor se explorar o rendimento de grãos dessas constituições genéticas. Isso se deve, principalmente, ao fato de os efeitos compensatórios dos componentes do rendimento de grãos serem dependentes do genótipo, do ambiente e da interação entre ambos (Atchley \& Zhu, 1997). Genótipos de trigo com menor capacidade de afilhamento são dependentes de elevada densidade de semeadura, já que possuem menor efeito compensatório do número de espigas por unidade de área, apesar de apresentarem maior fertilidade de espiguetas e maior massa de grãos por planta (Scheeren et al., 1995; Motzo et al., 2004). Além disso, genótipos com elevado potencial de afilhamento, de acordo com Richards (1988), apresentam maior incidência de afilhos inférteis, e são, portanto, dependentes do ajuste adequado da densidade de semeadura.
O objetivo deste trabalho foi acompanhar a emissão e sobrevivência de afilhos em genótipos de trigo contrastantes para esse caráter, cultivados em diferentes densidades de semeadura, e identificar os genótipos que evidenciassem o melhor efeito compensatório dos componentes do rendimento e maior plasticidade em relação às modificações do ambiente.

\section{Material e Métodos}

$\mathrm{O}$ experimento foi estabelecido no ano agrícola de 2006, em campo experimental do Centro de Genômica e Fitomelhoramento, da Faculdade de Agronomia Eliseu Maciel, Universidade Federal de Pelotas, no Município de Capão do Leão, RS. O município está a $31^{\circ} 52^{\prime} 0^{\prime \prime} \mathrm{S}$ e $52^{\circ} 21^{\prime} 24 " \mathrm{~W}$, a uma altitude de 13,24 m. O clima, segundo a classificação de Köppen, é do tipo Cfa, com precipitação pluviométrica média anual de $1.280 \mathrm{~mm}$ (Moreno, 1961). O solo é da classe Argissolo VermelhoAmarelo distrófico, de textura argilosa e relevo ondulado, com presença marcante do lençol freático próximo à superfície.

A análise química do solo foi realizada em amostras retiradas da profundidade de $0-20 \mathrm{~cm}$, antes da instalação do experimento. $\mathrm{O}$ solo apresentou as seguintes características: $1,5 \%$ de $\mathrm{MO} ; \mathrm{pH}$ em água de 5,7; 14,3 $\mathrm{mg} \mathrm{dm}^{-3}$ de P (Melich 1) e $74 \mathrm{mg} \mathrm{dm}^{-3}$ de K. Para a condução do experimento, a adubação de base consistiu da aplicação de $200 \mathrm{~kg} \mathrm{ha}^{-1}$ de $\mathrm{N}-\mathrm{P}_{2} \mathrm{O}_{5}-\mathrm{K}_{2} \mathrm{O}$ (5-20-20), mais $40 \mathrm{~kg} \mathrm{ha}^{-1}$ de $\mathrm{N}$ aplicado em cobertura, no início do afilhamento. $\mathrm{O}$ controle de pragas e doenças foi realizado de acordo com as recomendações da CSBPT-2006 (Comissão Sul-Brasileira de Pesquisa de Trigo, 2006).

Foram utilizados dez genótipos de trigo de origem brasileira, contrastantes quanto ao potencial de afilhamento: FUNDACEP 29; IPR 85; CD 108, CD 114 e OCEPAR 11-JURITI; SAFIRA; BRS FIGUEIRA, BRS UMBÚ, BRS 177 e BR 18. Os genótipos IPR 85, CD 108, OCEPAR 11-JURITI, FUNDACEP 29 e BR 18 foram escolhidos com base no reduzido potencial de afilhamento, e CD 114, BRS UMBÚ, BRS 177, SAFIRA e BRS FIGUEIRA, com base no elevado potencial. Todos os genótipos foram semeados com cinco diferentes densidades: 50, 200, 350, 500 e 650 sementes aptas por metro quadrado. As avaliações para o caráter número de afilhos foram realizadas em cinco épocas distintas: aos 20, 45 e 70 dias após emergência, no florescimento e na maturação. 
O delineamento experimental utilizado foi o de parcelas divididas, com três repetições, em que os fatores genótipo e densidade foram considerados como parcela e subparcela, respectivamente, e a época de avaliação foi considerada o terceiro fator experimental. Foram avaliados os seguintes caracteres em campo: número de afilhos (NA), por meio da contagem do número de afilhos de cada genótipo, em $1 \mathrm{~m}$ de cada subparcela nos cinco estádios de avaliação, em que a última contagem foi somente de afilhos férteis (NAF); número de grãos por espiga (NGE), por meio da contagem do número de grãos de sete espigas, escolhidas aleatoriamente em cada subparcela; e massa de grãos por espiga (MGE), obtida pela determinação da massa de grãos de sete espigas, escolhidas aleatoriamente em cada subparcela.

Os dados do NA, avaliados em campo, foram submetidos à análise de variância no esquema de parcelas divididas, com o programa computacional Winstat (Winstat, 2006), tendo-se considerado os fatores época de avaliação, genótipo e densidade como fixos, e o efeito de época aninhado aos efeitos de genótipo e densidade. Os efeitos da interação entre os fatores foram testados na análise de regressão linear, por meio do teste da significância dos distintos graus do polinômio, em função das diferentes épocas de avaliação, e apresentados na forma de gráficos individuais para cada genótipo. Os caracteres NGE e MGE, avaliados em laboratório, foram submetidos à análise de variância no esquema de parcelas divididas, tendo-se considerado os fatores genótipo e densidade como fixos. Os efeitos da interação entre estes fatores também foram testados na análise de regressão linear, por meio do teste da significância dos distintos graus do polinômio em função dos diferentes níveis do fator densidade, e também apresentados na forma de gráficos individuais.

\section{Resultados e Discussão}

A análise de variância do NA revelou diferença significativa $(\mathrm{p}<0,05)$ tanto para as épocas de avaliação, quanto para as interações. A presença da interação tripla - época de avaliação $\mathrm{x}$ densidade $\mathrm{x}$ genótipo - indica que há diferença de potencial de afilhamento entre o conjunto de genótipos avaliados e que a expressão do potencial de afilhamento é dependente da densidade de semeadura e da época de avaliação.

Em relação aos caracteres MGE e NGE, o efeito da interação genótipo $\mathrm{x}$ densidade não foi significativo. Isto revela, quanto aos genótipos avaliados, que a densidade de semeadura não exerce influência significativa para as diferentes médias desses caracteres, entre os genótipos. Os coeficientes de variação foram de 10,07 e 10,12\% para MGE e NGE, respectivamente, o que expressa boa precisão. Entretanto, em relação ao NA, a maior magnitude do coeficiente de variação $(15,87 \%)$ demonstra necessidade de maior controle das técnicas experimentais, como aumento do número de repetições e tamanho de parcela.

Os genótipos escolhidos com base no reduzido potencial de afilhamento apresentaram, de acordo com as diferentes épocas, diferente comportamento na produção de afilhos por metro, nas diferentes densidades avaliadas. Esses genótipos não diferiram entre as épocas e apresentaram comportamento linear, quadrático e cúbico do número de afilhos produzidos em relação à variação na época de avaliação (Figura 1). Nos genótipos com elevado potencial de afilhamento, o desempenho na produção de afilhos por metro, de acordo com as diferentes épocas, foi uniforme, com comportamento quadrático, exceto nos genótipos BRS Figueira, nas densidades de 500 e 600 sementes aptas por metro quadrado, e Safira, na densidade de 600 sementes aptas por metro quadrado (Figura 1). A diferença na produção de afilhos, em função das épocas de avaliação, observada entre os dois grupos de genótipos, mostra a maior contribuição da densidade de semeadura sobre a produção de afilhos, para os genótipos com reduzido potencial de afilhamento, o que ressalta a necessidade de condução destes genótipos em densidades adequadas, para uma maior contribuição do número de espigas por unidade de área na produtividade da cultura (Ozturk et al., 2006).

Conforme análise de variância para cada genótipo, no caráter NA, apenas o genótipo OCEPAR 11-JURITI não apresentou efeito significativo quanto à interação densidade de semeadura x época de avaliação, somente efeito simples de época. Isto mostra que, mesmo ao ser utilizada uma elevada densidade de semeadura neste genótipo, a produção de espigas por unidade de área não seria afetada. Quanto aos demais genótipos com reduzida capacidade de afilhamento, observa-se, na Figura 1, que o maior ponto de máxima para o caráter NA esteve sempre relacionado às maiores densidades, já que dependem do aumento na densidade para compensar seu reduzido afilhamento, fato também observado por Holen et al. (2001).

Nos genótipos com elevado potencial de afilhamento, observou-se grande variação nos pontos de máxima produção de afilhos por metro, de acordo com a densidade. Para esses genótipos, o ponto de máxima 

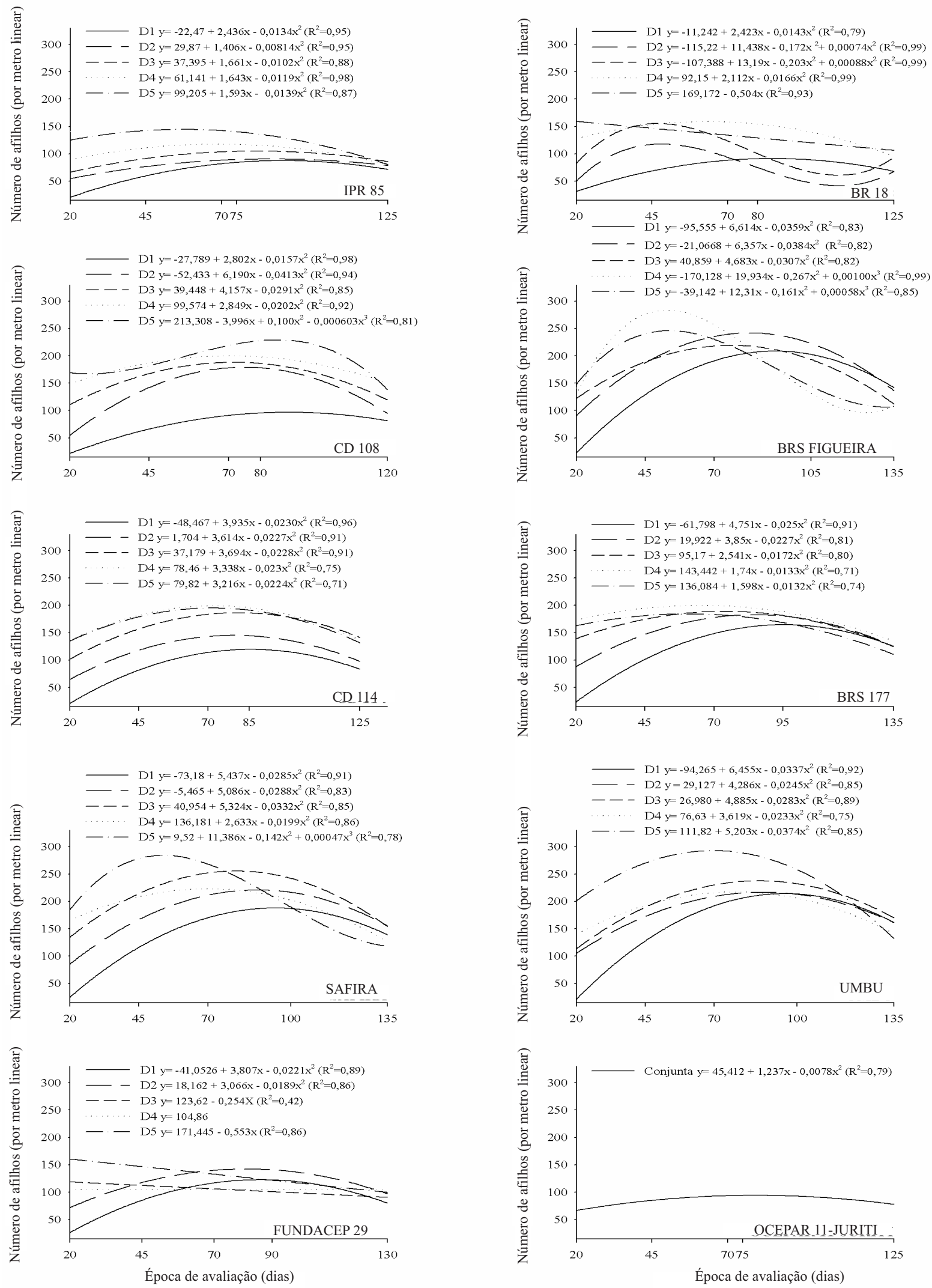

Figura 1. Número de afilhos de genótipos de trigo, testados em diferentes densidades de semeadura (D1 = 50, D2 $=200$, D3 $=350$, D4 $=500$ e D5 = 650 sementes aptas por metro quadrado), em cinco épocas de avaliação. 
produção de afilhos muitas vezes não esteve associado às maiores densidades de semeadura. Isto indica que, ao serem submetidos a elevadas densidades de semeadura, esses genótipos apresentarão queda na produção de afilhos, pela maior competitividade por luz e nutrientes. Este comportamento pode ser observado na Tabela 1 no genótipo SAFIRA, que apresentou ponto de máxima no NA (254 afilhos por metro) com 350 sementes aptas por metro quadrado, e decréscimo com o uso da densidade de 500 sementes aptas por metro quadrado (223 afilhos por metro).

É possível observar, na Tabela 1, que o aumento da densidade de semeadura ocasionou uma redução no número de dias para atingir a máxima produção de afilhos

Tabela 1. Resultados oriundos de valores calculados por equações de regressão e médias de caracteres, de genótipos de trigo em diferentes densidades ${ }^{(1)}$.

\begin{tabular}{|c|c|c|c|c|c|c|c|}
\hline Genótipo & $\begin{array}{c}\text { Densidade }^{(2)} \\
\left(\text { sementes } \mathrm{m}^{-2}\right)\end{array}$ & $\begin{array}{c}\text { MPA } \\
\left(\mathrm{n}^{\circ}\right)\end{array}$ & $\begin{array}{c}\text { EMPA } \\
\text { (dias) }\end{array}$ & $\begin{array}{l}\text { NAF } \\
\left(\mathrm{n}^{\circ}\right)\end{array}$ & $\begin{array}{c}\text { Perda } \\
\left(\mathrm{n}^{\circ}\right)\end{array}$ & $\begin{array}{l}\text { MGE } \\
(\mathrm{g})\end{array}$ & $\begin{array}{c}\text { NGE } \\
\left(\mathrm{n}^{\mathrm{o}}\right)\end{array}$ \\
\hline \multirow[t]{5}{*}{ IPR 85} & $\mathrm{D} 1$ & 87 & 90 & 71 & 16 & 2,34 & 52 \\
\hline & D2 & 95 & 86 & 78 & 17 & 2,12 & 45 \\
\hline & D3 & 105 & 81 & 85 & 20 & 2,11 & 44 \\
\hline & D4 & 118 & 69 & 80 & 38 & 1,97 & 40 \\
\hline & D5 & 145 & 57 & 80 & 65 & 1,73 & 38 \\
\hline \multirow[t]{5}{*}{ BRS FIGUEIRA } & D1 & 208 & 92 & 142 & 66 & 1,46 & 43 \\
\hline & D2 & 242 & 83 & 126 & 106 & 1,40 & 41 \\
\hline & D3 & 219 & 76 & 112 & 107 & 1,36 & 37 \\
\hline & D4 & - & $-^{(3)}$ & - & - & 1,30 & 31 \\
\hline & D5 & - & - & - & - & 1,11 & 30 \\
\hline \multirow[t]{5}{*}{ CD 108} & D1 & 96 & 89 & 81 & 15 & 1,79 & 51 \\
\hline & D2 & 179 & 75 & 94 & 85 & 1,26 & 38 \\
\hline & D3 & 188 & 71 & 119 & 69 & 1,22 & 37 \\
\hline & D4 & 200 & 70 & 150 & 50 & 1,20 & 33 \\
\hline & D5 & - & - & - & - & 1,16 & 36 \\
\hline \multirow[t]{5}{*}{ UMBU } & D1 & 240 & 96 & 161 & 79 & 1,82 & 58 \\
\hline & D2 & 216 & 87 & 160 & 56 & 1,75 & 50 \\
\hline & D3 & 237 & 86 & 170 & 67 & 1,55 & 45 \\
\hline & D4 & 217 & 78 & 140 & 77 & 1,48 & 44 \\
\hline & D5 & 292 & 69 & 132 & 160 & 1,42 & 41 \\
\hline \multirow[t]{5}{*}{ CD 114} & D1 & 119 & 85 & 83 & 36 & 2,13 & 55 \\
\hline & D2 & 145 & 80 & 98 & 47 & 1,97 & 49 \\
\hline & D3 & 186 & 80 & 141 & 45 & 1,64 & 43 \\
\hline & D4 & 199 & 72 & 136 & 63 & 1,64 & 43 \\
\hline & D5 & 195 & 72 & 131 & 64 & 1,53 & 41 \\
\hline \multirow[t]{5}{*}{ BRS 177} & D1 & 164 & 95 & 125 & 39 & 2,00 & 58 \\
\hline & D2 & 183 & 84 & 125 & 58 & 1,80 & 53 \\
\hline & D3 & 189 & 74 & 124 & 65 & 1,53 & 46 \\
\hline & D4 & 200 & 65 & 134 & 66 & 1,52 & 46 \\
\hline & D5 & 184 & 60 & 110 & 74 & 1,41 & 43 \\
\hline OCEPAR 11 -JURITI & Conjunta & 94 & 79 & 77 & 17 & 1,71 & 42 \\
\hline \multirow[t]{5}{*}{ SAFIRA } & D1 & 185 & 95 & 140 & 45 & 1,53 & 53 \\
\hline & D2 & 219 & 88 & 156 & 63 & 1,51 & 44 \\
\hline & D3 & 254 & 80 & 154 & 100 & 1,43 & 40 \\
\hline & D4 & 223 & 66 & 128 & 95 & 1,43 & 40 \\
\hline & D5 & - & - & - & - & 1,42 & 39 \\
\hline \multirow[t]{5}{*}{ FUNDACEP 29} & D1 & 123 & 86 & 80 & 43 & 2,17 & 60 \\
\hline & D2 & 142 & 81 & 97 & 45 & 2,07 & 58 \\
\hline & D3 & - & - & - & - & 1,98 & 56 \\
\hline & D4 & - & - & - & - & 1,81 & 55 \\
\hline & D5 & - & - & - & - & 1,73 & 49 \\
\hline \multirow[t]{5}{*}{ BR 18} & D1 & 91 & 85 & 68 & 23 & 2,15 & 42 \\
\hline & D2 & - & - & - & - & 1,98 & 40 \\
\hline & D3 & - & - & - & - & 1,93 & 39 \\
\hline & D4 & 159 & 63 & 96 & 63 & 1,78 & 34 \\
\hline & D5 & - & - & - & - & 1,72 & 29 \\
\hline
\end{tabular}

(1)MPA: máxima produção de afilhos; EMPA: época de máxima produção de afilhos; NFA: número de afilhos férteis; Perda: perda na produção de afilhos ao longo do desenvolvimento da planta; MGE: média da massa de grãos por espiga; NGE: média do número de grãos por espiga. (2)D1 = 50, $\mathrm{D} 2=200, \mathrm{D} 3=350, \mathrm{D} 4=500$ e D5 $=650$ sementes aptas por metro quadrado. ${ }^{(3)}$ Dados que não apresentaram comportamento quadrático. 
por metro, em todos os genótipos avaliados. Com a exceção do genótipo CD 108, pôde-se observar menor taxa de sobrevivência de afilhos no final do ciclo, à medida que se aumentou a densidade de plantio. Esse fato está relacionado à modificação precoce na qualidade da luz, causada pelo sombreamento, e à maior competição entre plantas, o que afeta o crescimento foliar do colmo principal e dos afilhos (Almeida et al., 2004).

A perda na produção de afilhos esteve relacionada ao número de afilhos férteis durante o desenvolvimento das plantas, especialmente nos genótipos de elevado potencial de afilhamento. Essa relação pode ser constatada, por exemplo, nos genótipos IPR 85 e BRS UMBU, respectivamente de reduzido e elevado potencial de afilhamento, que obtiveram a maior produção de NAF, na densidade de 350 sementes aptas por metro quadrado, e apresentaram grande diferença na senescência de afilhos ao longo do desenvolvimento das plantas, com perda respectiva de 20 e 67 afilhos por metro, nesta mesma densidade (Tabela 1). Portanto, ao se compararem os dois grupos de genótipos quanto à senescência de afilhos, deve-se enfatizar a necessidade de considerar o potencial do genótipo em produzir afilhos, para a escolha da densidade de semeadura mais apropriada.

Os genótipos de elevado potencial de afilhamento apresentam maior período de produção de afilhos, em virtude do longo ciclo de desenvolvimento (Tabela 1), o que está de acordo com a maior senescência de afilhos, observada neste grupo de genótipos, visto que os afilhos emitidos tardiamente apresentam menor capacidade de competição e reduzida taxa de sobrevivência (Dofind $\&$ Karlsson, 1993). Segundo Common \& Klinck (1981), o ideal seria que as plantas apresentassem, além do colmo principal, dois ou três afilhos, para minimizar a perda de afilhos produtivos.

No desempenho conjunto dos genótipos avaliados para o caráter MGE, sob os diferentes níveis de densidade, observou-se comportamento linear negativo (Figura 2). A possível explicação para isto deve-se à grande competição, entre plantas, pelos recursos do ambiente durante seu desenvolvimento. Segundo Whaley et al. (2000), com o aumento da competição entre plantas (altas densidades), há redução do dossel, o que reduz muito a MGE, resultados também verificados no presente trabalho. Além disso, em reduzidas densidades há incremento na taxa de crescimento da planta, com maior eficiência na radiação capturada, ou ainda, com melhor conversão da radiação em assimilados (Whaley et al., 2000).

A diminuição da MGE com o aumento da densidade é acentuada em genótipos com maior afilhamento (Tabela 1). Isto pode ser atribuído ao fato de esses genótipos produzirem um elevado número de espigas por unidade de área, independentemente da densidade e da duração do ciclo, o que ocasiona maior efeito de competição por fotoassimilados e, conseqüentemente, menor enchimento dos grãos. Nos genótipos com reduzido afilhamento, a eficiência na utilização de fotoassimilados se deve ao maior efeito compensatório destes genótipos, com maior MGE em detrimento do
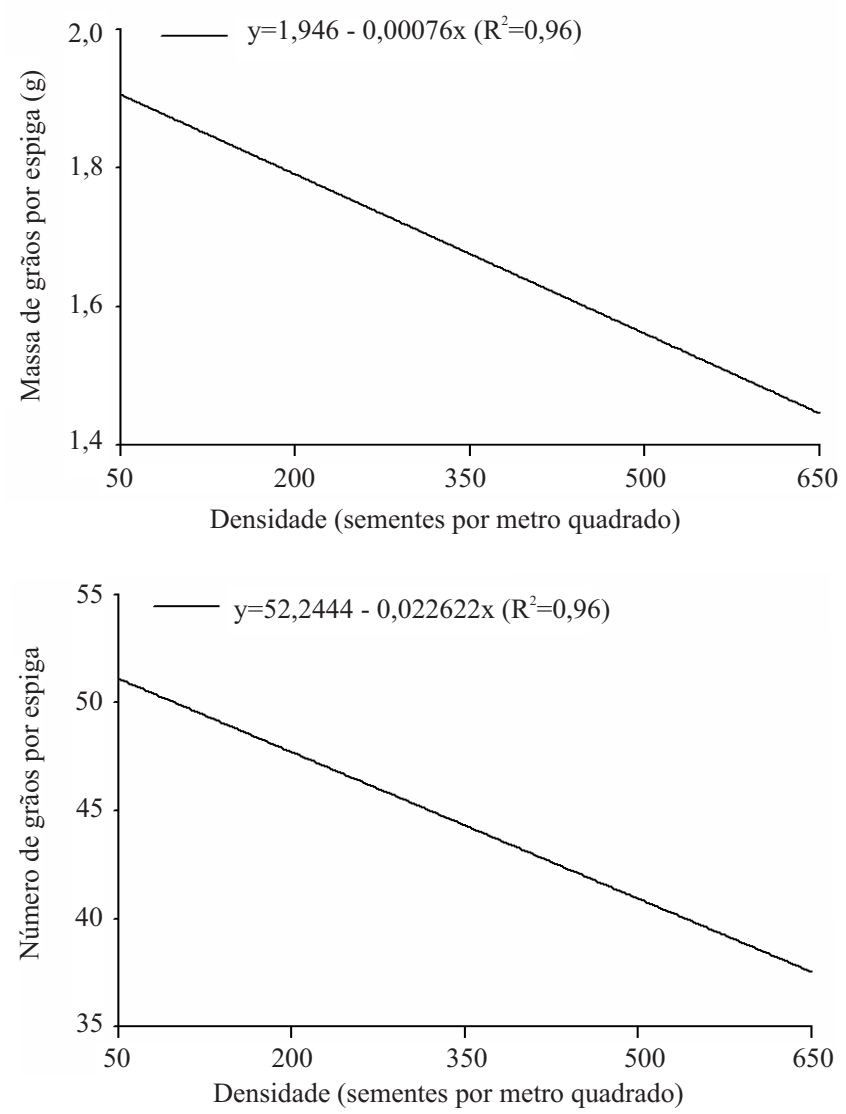

Figura 2. Média da massa de grãos por espiga e número de grãos por espiga, dos genótipos de trigo IPR 85, BRS FIGUEIRA, CD 108, UMBU, CD 114, BRS 177, OCEPAR 11-JURITI, SAFIRA, FUNDACEP 29 e BR 18, testados em diferentes densidades de semeadura. 
número de espigas por unidade de área (Scheeren et al., 1995). O efeito compensatório pôde ser constatado, no presente trabalho, para o grupo de genótipos com reduzido afilhamento, pela superioridade na média do caráter MGE, em todas as densidades avaliadas (Tabela 1). Observou-se, também, maior precocidade dos genótipos com reduzido afilhamento, o que aliado à maior sobrevivência de afilhos por metro pode aumentar o potencial de aproveitamento deste grupo de genótipos em áreas marginais, por minimizar os riscos de perdas por geadas, estresses hídricos, chuva na colheita e controle de doenças foliares.

Mesmo não tendo sido observada a presença de interação significativa entre NGE $\mathrm{x}$ densidade, a constatação de efeito linear negativo do aumento na densidade sobre esse caráter está de acordo com resultados da literatura (Whaley et al., 2000; Holen et al., 2001; Lloveras et al., 2004; Arduini et al., 2006). Este fato pode estar associado à maior competição por luz e nutrientes, resultantes da maior população de afilhos férteis por unidade de área (Ozturk et al., 2006). Com relação às médias observadas para o caráter NGE, os dois grupos de genótipos testados evidenciaram comportamento similar (Tabela 1).

\section{Conclusões}

1. A senescência de afilhos é relacionada diretamente ao potencial de afilhamento dos genótipos, principalmente com densidade de semeadura elevada.

2. Genótipos com reduzido potencial de afilhamento são mais dependentes da densidade de semeadura, em termos produtivos.

\section{Agradecimentos}

À Coordenação de Aperfeiçoamento de Ensino Superior, ao Conselho Nacional de Desenvolvimento Científico e Tecnológico e à Fundação de Amparo à Pesquisa no Estado do Rio Grande do Sul, pelo suporte financeiro.

\section{Referências}

ALMEIDA, M.L.; SANGOI, L.; MEROTTO JÚNIOR, A.; ALVES, A.C.; NAVA, I.C.; KNOPP, A.C. Tiller emission and dry mass accumulation of wheat cultivars under stress. Scientia Agricola, v.61, p.266-270, 2004.
ARDUINI, I.; MASONI, A.; ERCOLI, L.; MARIOTTI, M. Grain yield, and dry matter and nitrogen accumulation and remobilization in durum wheat as affected by variety and seeding rate. European Journal of Agronomy, v.25, p.309-318, 2006.

ATCHLEY, W.R.; ZHU, J. Developmental quantitative genetics, conditional epigenetic variability and growth in mice. Genetics, v.147, p.765-776, 1997.

COMISSÃO SUL BRASILEIRA DE PESQUISA DE TRIGO. Informações técnicas da Comissão Sul-Brasileira de Pesquisa de Trigo e Triticale para a Safra 2006. Passo Fundo: EmbrapaCNPT, 2006. 159p.

COMMON, J.C.; KLINCK, H.R. Sequence and synchrony of culm development: implications in breeding for limited tillering barleys. In: International Barley Genetics Symposium, 4., 1981, Edinburg, Scotland. Proceedings. Edinburgh: Univ. Press, 1981. p.533-536.

DAVIDSON, D.J.; CHEVALIER, P.M. Preanthesis tiller mortality in spring wheat. Crop Science, v.30, p.832-836, 1990.

DOFING, S.M.; KARLSSON, M.G. Growth and development of uniculm and conventional-tillering barley lines. Agronomy Journal, v.85, p.58-61, 1993.

FREEZE, D.M.; BACON, R.K. Row-spacing and seeding rate effects on wheat yields in the Mid-South. Journal of Production Agriculture, v.3, p.345-348, 1990.

HOLEN, D.L.; BRUCKNER, P.L.; MARTIN, J.M.; CARLSON, G.R.; WICHMAN, D.M.; BERG, J.E. Response of winter wheat to simulated stand reduction. Agronomy Journal, v.93, p.364-370, 2001.

LLOVERAS, J.; MANENT, J.; VIUDAS, J.; LÓPEZ, A.; SANTIVERI, P. Seeding rate influence on yield and yield components of irrigated winter wheat in a Mediterranean climate. Agronomy Journal, v.96, p.1258-1265, 2004.

MORENO A.J. Clima do Rio Grande do Sul. Porto Alegre: Secretaria da Agricultura, 1961.41p.

MOTZO, R.; GIUNTA, F.; DEIDDA, M. Expression of a tiller inhibitor gene in the progenies of interspecific crosses Triticum aestivum L. x T. turgidum subsp. durum. Field Crops Research, v.85, p.15-20, 2004.

MUNDSTOCK, C.M. Planejamento e manejo integrado da lavoura de trigo. Porto Alegre: Ed. do Autor, 1999. 228p.

OZTURK, A.; CAGLAR, O.; BULUT, S. Growth and yield response of facultative wheat to winter sowing, freezing sowing and spring sowing at different seeding rates. Journal of Agronomy and Crop Science, v.192, p.10-16, 2006.

RICHARDS, R.A. A tiller inhibition gene in wheat and its effect on plant growth. Australian Journal of Agricultural Science, v.39, p.749-757, 1988. 
SCHEEREN, P.L.; CARVALHO, F.I.F.; FEDERIZZI, L.C. Resposta do trigo aos estresses causados por baixa luminosidade e excesso de água no solo. Parte II: Teste no campo. Pesquisa Agropecuária Brasileira, v.30, p.605-619, 1995.

SPARKES, D.L.; HOLME, S.J.; GAJU, O. Does light quality initiate tiller death in wheat? European Journal of Agronomy, v.24, p.212-217, 2006.
WHALEY, J.N.; SPARKES, D.L.; FOULKES, M.J.; SPINK, J.H.; SCOTT, R.K. The physiological response of winter wheat to reductions in plant density. Annals of Applied Biology, v.137, p.164177,2000 .

WINSTAT. Sistema de análise estatística para Windows. Pelotas: Ufpel, 2006.

Recebido em 25 de outubro de 2007 e aprovado em 26 de fevereiro de 2008 